\title{
Profile of vintafolide (ECI45) and its use in the treatment of platinum-resistant ovarian cancer
}

This article was published in the following Dove Press journal:

International Journal of Women's Health

31 March 2014

Number of times this article has been viewed

\author{
Mathieu Luyckx ${ }^{1,2}$ \\ Raffaella Votino' \\ Jean-Luc Squifflet ${ }^{1,2}$ \\ Jean-François Baurain ${ }^{2,3}$ \\ 'Gynecology and Andrology Unit, \\ ${ }^{2}$ Centre du cancer, Gynecologic \\ Oncology Group, ${ }^{3}$ Medical Oncology \\ Unit, Cliniques Universitaires Saint- \\ Luc, Brussels, Belgium
}

Objective: Our aim was to review the profile of vintafolide (EC145) and its rationale for use in platinum-resistant ovarian cancer. First we investigated the folate receptors (FRs), folate's pathway into cells, and its expression in normal and cancerous cells, before detailing the mechanism of action of vintafolide, its clinical applications, and the results of different study phases.

Materials and methods: A literature search was conducted through PubMed/Medline, Google, ClinicalTrials.gov and websites of pharmaceutical companies. Only articles in English were selected. All articles investigating folate receptor expression in ovarian cancer were selected first, than articles reviewing platinum resistance. Papers about vintafolide were collected, while those talking about synthesis and biochemistry concerns were excluded. The different Phase I and II studies were read, and an update on the website of pharmaceuticals companies were added.

Results: FR is a bundle-membrane receptor that is expressed normally in some normal tissues on the apical surface of cells, but highly expressed in ovarian cancer cells $(>80 \%)$. It collects folate through endocytosis. Chemotherapy does not modify its expression in ovarian cancer cells, and its expression appears to be mostly associated with a poor prognosis and platinum resistance. Vintafolide is a folate-desacetylvinblastine monohydrazide conjugate, allowing a liberation of the drug into the cytoplasm of cancerous cells via the FR- $\alpha(F R \alpha)$ and endocytosis, with high specificity. Phase I studies showed a $2.5 \mathrm{mg}$ bolus dose to be nontoxic, with moderately adverse events. Phase II clinical trials for the first time demonstrated a statistically significant improvement in disease-free survival in patients with platinum-resistant ovarian cancer, and in those with a very poor prognosis who had already received three to four lines of systemic chemotherapy. The greater benefits were observed in patients with highly expressed FR $\alpha$.

Conclusion: Vintafolide is a promising targeted agent for recurrent platinum-resistant ovarian cancer, first, thanks to its mechanism of action and the characteristics of FR $\alpha$ in ovarian cancer, and, second, because of the favorable results observed in the first clinical trials on platinumresistant ovarian cancer. Phase III clinical trials are currently ongoing and are expected to confirm these results.

Keyword: folate receptor, platinum-resistant ovarian cancer, chemotherapy

\section{Introduction}

Epithelial ovarian cancer (EOC) is the most deadly cancer of all gynecologic malignancies in the world, ${ }^{1}$ accounting for $4 \%$ of all cancers in women, and the fifth leading cause of cancer-related death among women. In 2013, 22,240 new cases are estimated to be diagnosed in the United States, and it is estimated that 14,030 deaths will occur because of ovarian cancer this same year in the United States. ${ }^{2}$ The incidence is nearly twice as high in developing countries. Presenting few symptoms at an early stage, the pathology is almost always detected at an advanced stage. Conventional treatment is
Correspondence: Mathieu Luyckx Service de Gynécologie et Andrologie, Cliniques Universitaires Saint-Luc, I0, Avenue Hippocrate, 1200 Bruxelles, Belgium

Tel +32 27649509

Fax +32 27649507

Email mathieu.luyckx@uclouvain.be (c) (i) (9) 2014 Luyckx et al. This work is published by Dove Medical Press Limited, and licensed under Creative Commons Attribution - Non Commercial (unported, v3.0) License. The full terms of the License are available at http://creativecommons.org/licenses/by-nc/3.0/. Non-commercial uses of the work are permitted without any further permission from Dove Medical Press Limited, provided the work is properly attributed. Permissions beyond the scope of the License are administered by Dove Medical Press Limited. Information on how to request permission may be found at: http://www.dovepress.com/permissions.php 
based on aggressive surgery associated with platinum-based chemotherapy. Advances in the two arms of treatment were seen in the last decade; more aggressive surgery leaving no residual disease at the end of the procedure yielded considerable improvements in disease-free survival (DFS) and overall survival (OS) at advanced stages. ${ }^{3}$ Regarding medical treatment, a combination of paclitaxel and cisplatin has shown the most survival benefits ${ }^{4}$ and is currently the standard treatment. Dose-dense paclitaxel ${ }^{5}$ and more recent targeted therapies have reinforced the therapeutic arsenal. Despite all these improvements, EOC survival remains low worldwide, ${ }^{6}$ except in some trials by a leading team. ${ }^{3}$ The world-recognized team of Chi et al, at Memorial SloanKettering Cancer Center, showed median OS in a group of patients with complete primary cytoreductive surgery of 106 months. ${ }^{7}$ New strategies for EOC treatment are therefore needed and are under development.

Folate is a water-soluble vitamin of the B class, naturally found in most vegetables. It plays an important role in DNA synthesis and DNA methylation related to the methionine metabolic pathway. Folate leakage could lead to DNA hypermethylation and gene expression, and also to chromosome damage, both key factors for carcinogenesis. ${ }^{8}$ Paradoxically, when cancer is established, there is increasing evidence that folate can enhance its progression in some carcinomas (colon and rectum, breast, and prostate). ${ }^{9}$
The folate pathway is currently the subject of extensive study, and numerous trials are underway using different mechanisms to interfere with the pathway or to divert its normal transport system into the cytoplasm of the cell in order to selectively introduce chemotherapeutic agent into the cancerous cell. One of these promising agents is vintafolide (EC145). Herein, we review the profile of vintafolide and the rationale for its use in platinum-resistant ovarian cancer treatment.

\section{Materials and methods}

A literature search was performed in PubMed/medline, Google, ClinicalTrials.gov and web site of pharmaceutical companies using the terms "vintafolide - EC145 and ovarian cancer," "folate receptor," and "platinum-resistant ovarian cancer." Only articles in English were selected. All articles investigating folate receptor expression in ovarian cancer were selected first, than articles reviewing platinum resistance. Papers about vintafolide were collected, while those talking about synthesis and biochemistry concerns were excluded. The different Phase I and II studies were read, and an update on the website of pharmaceuticals companies were added.

\section{Folate receptor}

There are two main ways for cells to collect folate. One way is via the reduced folate carrier (RFC), a bidirectional

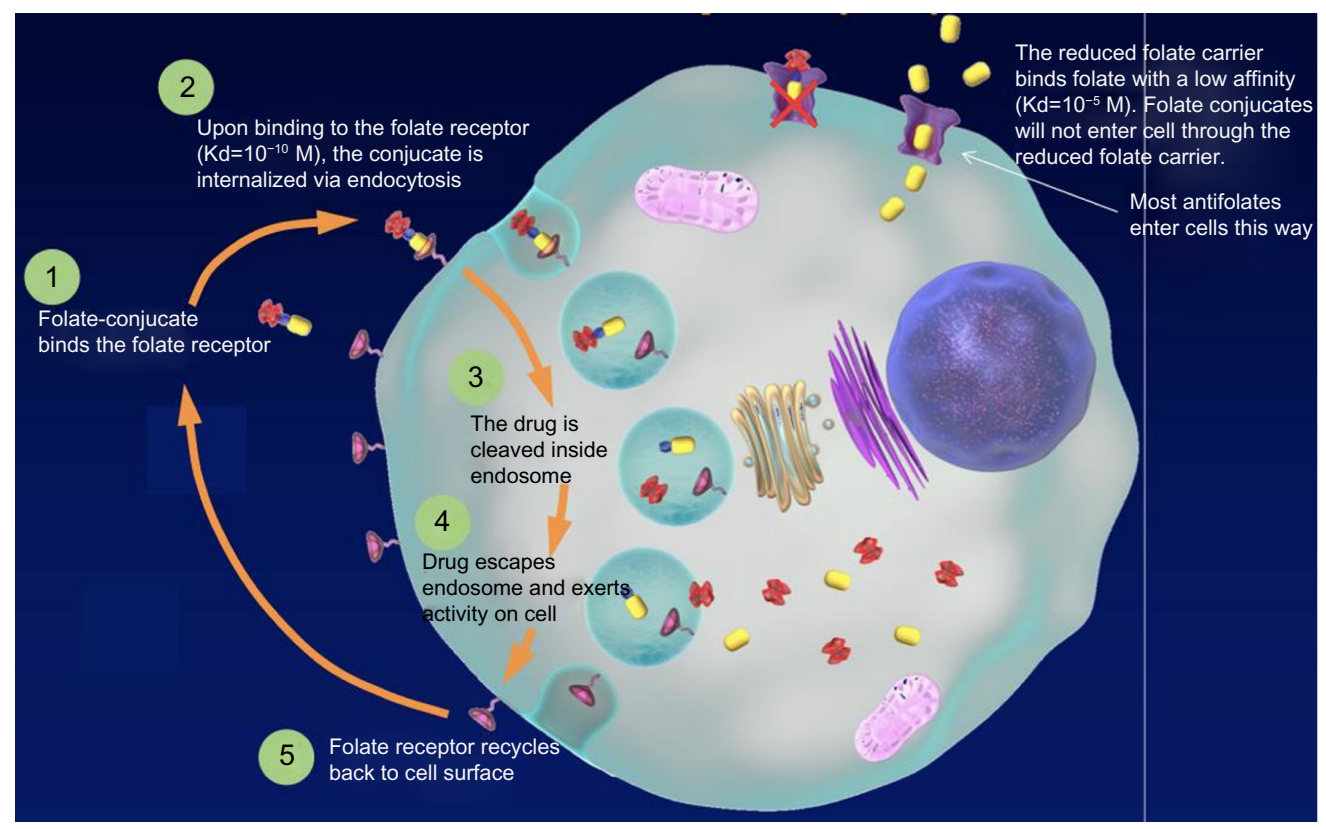

Figure I The two folate receptors (reduced folate carrier and folate receptor- $\alpha$ ) and the mechanism of action of vintafolide.

Notes: Reduced folate carrier binds folate with low affinity but have a very high transport capacity, and most of the folate enters the cell that way. Conjugate folate can not use the reduced folate carrier. When folate receptor- $\alpha$ binds with folate (and here with folate conjugate), the receptor and the folate are internalized via endocytosis. In the endosome, changes in $\mathrm{pH}$ lead to separation of the folate from the receptor (and the conjugate from the folate if vintafolide is used). The folate is then liberated in the cell, and, when conjugated, drug is free to exert its activity on the cell. The receptor is recycled to the cell membrane. Reprinted with permission from Leamon CP, Reddy JA, Haines B, Dussault I. Vintafolide: a first-in-class small molecule drug conjugate targeting folate receptor-positive tumors. Poster \#5502/I2.54 
transporter with low affinity for folate and classical antifolates, but very high capacity for transport. RFC is ubiquitously expressed. ${ }^{10}$ In colorectal cancer, promotion of lesion progression was observed when RFC was lost. ${ }^{11}$

The other way is via the Folate receptor (FR), a glycosylphosphatidylinositol-linked membrane protein of 38-40 kDa, preferentially linked to oxidized folate. ${ }^{12}$ It enhances folate through endocytosis, showing very high affinity but low capacity. Since the macromolecule remains intact in the endosome, it can fully exert its function inside the cell. ${ }^{13}$ After endocytosis, FR is recycled, returning to the cell surface to bind to new folate (Figure 1).

Three isoforms have been described: $\alpha, \beta$, and $\gamma$. The $\alpha$-isoform (FR $\alpha$ ) is the most widely studied. In normal tissues, FR is mostly located on the apical surface of polarized epithelial cells, far away from the blood stream, ${ }^{14}$ and its role in reabsorbing folate from the filtrate via transcytosis in kidneys is well known. ${ }^{15} \mathrm{FR}-\beta$ is mostly found in the spleen, placenta, and white blood cells, and has different stereospecificities and affinities for folate coenzymes and antifolates. ${ }^{16}$ FR $-\gamma$ is found principally in bone marrow. ${ }^{17}$

\section{Expression of $\mathbf{F R}$ and ovarian cancer}

FR $\alpha$ is an interesting biological target in ovarian cancer. First, its expression is reported in the majority of non-mucinous ovarian cancers, with different percentages of ovarian cancer expressing FR $\alpha$ in the different literature reports (ranging from $80 \%$ to $100 \%$ of the different ovarian cancers tested positive for FR $\alpha$ ). These differences probably depend on the studied population, the type of cancer, and the method used to evaluate the receptor expression in the tissues. ${ }^{18}$ Table 1 summarizes the percentage results of the ovarian cancerexpressing FR in the literature. The results are, as previously mentioned, in the same range of expression, with the highest levels of FR $\alpha$ expression in serous-type ovarian cancer. Methods of detection also influence the results. Wu et al have extensively discussed the limitation of immunohistochemical staining, ${ }^{19}$ with this method the difficulty to quantitatively evaluate the intensity of expression. Recently, some authors evaluated FR $\alpha$ expression levels through semiquantitative reverse-transcription polymerase chain reaction, and showed that, for patients with a high expression of FR $\alpha$, DFS and OS were shorter than in patients with low FR $\alpha$ expression. ${ }^{20}$

The influence of FR $\alpha$ in prognoses varies from one study to another; some authors show no difference in OS and DFS between patients with ovarian cancer that expresses FR and those with ovarian cancer that does not. ${ }^{18,21,22}$

More recently, Siu et al found that FR $\alpha$ overexpression was associated with tumor progression, but also, for the first time, that high levels of RFC play a protective role. ${ }^{23}$ This is probably why other researchers have found it difficult to investigate the impact of FR $\alpha$ overexpression on OS and DFS in other studies. Toffoli et al, for example, showed that overexpression of FR predicted chemotherapy failure in ovarian cancer, ${ }^{24}$ but only in patients with residual disease after primary debulking surgery, known to have the worst prognosis. ${ }^{25}$

Table I Studies reporting proportion of ovarian cancer expressing folate receptor (FR)- $\alpha$

\begin{tabular}{|c|c|c|c|c|}
\hline Study & Number of patients & Method & FR expression & Survival \\
\hline Toffoli et $\mathrm{al}^{49}$ & 136 & Cytofluorometric & $89.7 \%$ all types & Not investigated \\
\hline \multirow[t]{3}{*}{ Wu et al ${ }^{19}$} & 23 & In situ hybrid & $100 \%$ serous & Not investigated \\
\hline & & Histochemistry & $80 \%$ endometrioid & \\
\hline & & & $0 \%$ clear cell & \\
\hline Bagnoli et $\mathrm{al}^{50}$ & 168 & Immunochemistry & $85.1 \%$ nonmucinous & Not investigated \\
\hline \multirow[t]{4}{*}{ Parker et $\mathrm{al}^{51}$} & 29 & Radioligand binding assay & $100 \%$ serous & Not investigated \\
\hline & & Immunochemistry & $100 \%$ endometrioid & \\
\hline & & & $36 \%$ mucinous & \\
\hline & & & $100 \%$ metastatic & \\
\hline \multirow[t]{5}{*}{ Kelemen et $\mathrm{al}^{52}$} & 97 & Immunochemistry & $67 \%$ serous & Not investigated \\
\hline & & & $67 \%$ endometrioid & \\
\hline & & & $75 \%$ clear cell & \\
\hline & & & $0 \%$ mucinous & \\
\hline & & & $0 \%$ others & No influence ${ }^{a}$ \\
\hline \multirow[t]{4}{*}{ Crane et al $^{18}$} & 361 & Immunochemistry & $81.8 \%$ serous & \\
\hline & & & $21.7 \%$ endometrioid & \\
\hline & & & $54.5 \%$ mucinous & \\
\hline & & & $80 \%$ clear cell & No influence ${ }^{a}$ \\
\hline Despierre et $\mathrm{a}^{21}$ & 41 & Immunochemistry & $100 \%$ all types & Not investigated \\
\hline O'Shannessy et $\mathrm{al}^{53}$ & 70 & & $100 \%$ serous & \\
\hline
\end{tabular}

Note: aNo influence of FR's expression on survival found. 
Interestingly, chemotherapy treatment did not modify FR expression in ovarian cancer, as recently demonstrated by Despierre et al, ${ }^{21}$ who studied 42 patients from whom biopsies were taken before and after chemotherapy. They found no modification in FR expression by chemotherapy, whether the biopsies were obtained from the same disease (diagnostic laparoscopy and debulking surgery after neoadjuvant chemotherapy) or from a recurrence. Previously, in 2012, Crane et al had already shown the same profile of FR $\alpha$ expression before and after chemotherapy. ${ }^{18}$ These observations reinforced the rationale for using FR $\alpha$ as a target for new treatments in ovarian cancer, especially when the disease was resistant to, or quickly recurred with, platinum-based chemotherapy, since the expression profile of FR $\alpha$ was not modified and platinum-resistant patients more frequently showed a high level of FR expression.

As it is often expressed specifically on the surface of cancerous cells, FR is a good target, either by taking advantage of its high affinity for folic acid and the endocytosis system or as an immunologic target for antibodies.

\section{Platinum-resistant ovarian cancer}

Platinum is recognized and widely employed as an anticancer drug. It is an alkylating anticancer drug, which induces cellular apoptosis. ${ }^{26}$ The platinum penetrates the cytoplasm via a membrane transporter (CTR1). It then undergoes an aquation reaction in order to activate it and giving it a high affinity for the ADN and fusion to the nucleus. ${ }^{27}$ It causes DNA damage by binding DNA and creating inter- or intra-strand cross-linkage. ${ }^{28}$ These lesions result in breaks in single- or double-strand DNA, and trigger activation of two different kinds of repair pathway: single-strand lesions are repaired by nucleotide excision repair and base excision repair systems, and double-strand lesions are repaired by homologous recombination (HR) system. Activation of these repair systems blocks the cell in the S or G2 phase. DNA damage cannot be repaired, and replication and transcription processes are stopped, inducing cellular apoptosis. Anomalies in one of these mechanisms cause platinum resistance.

A clinical classification of resistance was made, based on the time between the end of the first treatment and recurrence: ${ }^{29}$ 1) refractory with progression during the first chemotherapy; 2) resistant to platinum (recurrence within 6 months); or 3) sensitive (recurrence after 6 months or after 1 year). Over 17 spontaneous or acquired mechanisms of resistance to platinumbased chemotherapy have been described in ovarian tumor cells, including anomalies in repair pathways, anomalies in the distribution of platinum in tumor cells (reduced penetration or increase in its elimination by multidrug resistance-associated protein 2 [MRP2]), and anomalies in cellular metabolism, especially upregulation of specific biochemical pathways. ${ }^{30}$ Especially for folate, in vitro studies have identified a correlation between folate-binding protein expression and cisplatin sensitivity in ovarian cancer cell lines. ${ }^{31}$ Nevertheless, $75 \%$ of high-grade serous ovarian cancers develop progressive resistance to chemotherapy, which is known as acquired resistance. ${ }^{32}$ The current strategy for platinum-refractory and platinum-resistant tumors is to use monotherapy without platinum (gemcitabine, topotecan, liposomal doxorubicin with or without trabectedin, or paclitaxel). ${ }^{33}$ In such cases, a better understanding of ovarian cancer biology will allow us to consider new molecular targeted agents. A number of promising molecular targeted agents have been the focus of recent clinical trials, including agents that target vascular endothelial growth factor ([VEGF] and VEGF receptors) like bevacizumab, poly(adenosine diphosphate ribose) polymerase (PARP) inhibitor such as olaparib and iniparib, tumor suppressor gene PTEN (phosphatase and tensin homolog) conjugated FR agents (vintafolide, originally known as EC145). ${ }^{34}$

\section{Vintafolide}

To reduce the general toxicity of cytotoxic drugs used in cancer treatment, while at the same time increasing the quantity of drugs delivered directly to pathologic cells, a combination of chemotherapeutic agents and target molecules for specific receptors on cells appears to be a good option. As already mentioned, FR is a good target, and folic acid has a high affinity for FR.

Vintafolide is a folate-desacetylvinblastine monohydrazide (DAVLBH) conjugate..$^{35}$ It is a construct of folic acid conjugated to the microtubule-destabilizing agent DAVLBH via a self-immolative disulfide-based linker system (Figure 2) ${ }^{36}$

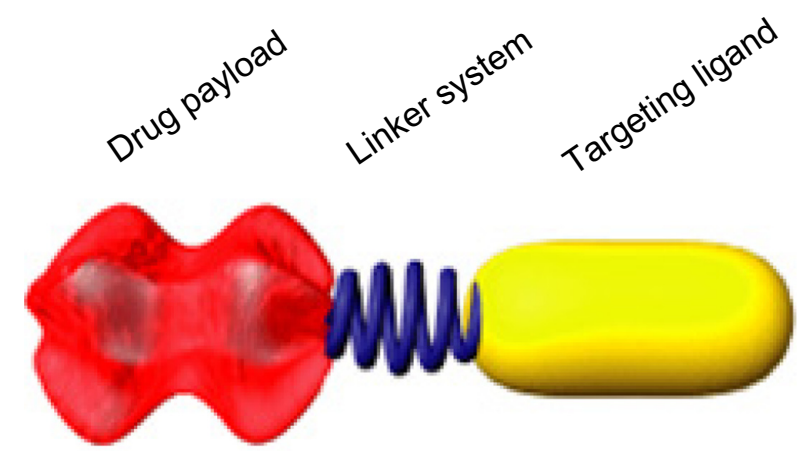

Figure 2 Vintafolide model.

Note: Illustration of the different components of vintafolide and the way they conjugate. Folate in yellow is conjugated with the DAVLBH in red via a disulfidebased linker system. Reprinted with permission from Leamon CP, Reddy JA, Haines B, Dussault I. Vintafolide: a first-in-class small molecule drug conjugate targeting folate receptor-positive tumors. Poster \#5502/1 $2 .^{54}$

Abbreviation: DAVLBH, desacetylvinblastine monohydrazide. 
DAVLBH is a vinca alkaloid that can prevent microtubule formation during mitosis of the cell, thereby inhibiting cell proliferation and leading to the cell death. In this model, EC145 is endocytosed in the tumoral cell after binding to the FR $\alpha$ with high affinity, then releases free drugs thanks to biologically relevant $\mathrm{pH}$ (in the endocyte) via sulfhydryl-assisted cleavage of the disulfide linker, ${ }^{24}$ leading to liberation of DAVLBH in the cytoplasm of the cancerous cell, which allows it to move quickly to the nucleus where it can play its role (Figure 1). It cannot enter cells through $\mathrm{RFC}$, so it is highly specific for cancer cells.

\section{Preclinical study}

Vintafolide was studied preclinically in mice. ${ }^{36} \mathrm{FR} \alpha$-positive nasopharyngeal KB cells and J6456 murine lymphoma cells were injected into the subcutaneous medial area of the mice. Vintafolide was administered intravenously. Different regimen schedules were tested. An excellent anti-tumoral effect was noted, with $5 / 5$ subjects showing a complete response in the first series of tests, and 4/5 maintaining this complete response up to 90 days (end of the study). No weight loss was noted with this first dose of $2 \mu \mathrm{mol} / \mathrm{kg}$. Accessibility to large-volume tumoral masses was good, with a marked response when large tumors were tested. Imaging with fluorescent folate-rhodamine conjugate test confirmed that, even in case of large tumors, cells within the malignant mass remained accessible to systematically administered folate-targeted agent. Regimen schedule testing showed a superior effect with daily administration of small doses, with rapid accumulation in tumoral tissue, compared with in the liver to saturation with a dose of $3 \mu \mathrm{mol} / \mathrm{kg}$. The efficacy of EC145 was excellent, with no significant added toxicity, and much better than DAVLBH alone, which produced toxicities to obtain a partial response.

\section{Phase I study}

The aim of the Phase I study by Lorusso et $\mathrm{al}^{37}$ was to determine the maximal tolerated dose of vintafolide in patients with solid refractory tumors. Two administration sequences were tested: a single bolus of the whole dose, or a 1-hour infusion of the same dose, given on days 1, 3, and 5 and days 15,17 , and 19 of each 28 -day cycle. Patients were allowed to undergo additional cycles when the first one was complete, until disease progression. For the bolus, the maximal dose tested was $4 \mathrm{mg}$, but patients experienced grade 2 constipation. For the 1-hour infusion group, with $3 \mathrm{mg}$, patients also developed grade 2 constipation. The maximal tolerated dose was therefore determined to be $2.5 \mathrm{mg}$, either for a bolus or for 1-hour infusion, as no dose-limited toxicity was encountered. Gastrointestinal toxicity was probably due to incapacity of the hepatobiliary metabolism to fully eliminate metabolites ${ }^{38}$ as evidenced in some preclinical studies. The constipation was easily managed with stool softeners and bowel-stimulating agents. ${ }^{38}$ Other commonly reported toxicities were nausea, fatigue, and vomiting, but no grade 4 toxicity attributed to the medication was observed in either the bolus group or the infusion group. Some cases of grade 1 and 2 neuropathy were reported. There were no medication-related deaths, but three deaths did occur in the 32 treated patients, due to complications underlying the disease. Pharmacokinetic parameters for EC145 were also investigated and reported, revealing levels of EC145 consistent with those necessary for cytotoxicity, through targeting of FR. Vintafolide was characterized by a short half-life, which indicates quick uptake by FR-expressing tissue. Regarding anti-tumoral activity, one patient with metastatic ovarian cancer presented with a partial response of 111 days' duration, showing shrinkage of tumoral masses and a decrease in the CA-125 level. Another patient with ovarian cancer maintained a stable disease state with EC145 and exhibited a decrease in the CA-125 level. On the basis of these observations, the Phase II study was initiated in ovarian cancer patients.

\section{Phase II study: PRECEDENT}

Recently published online and partially presented at the American Society of Clinical Oncology (ASCO) meetings of 2010 and 2011, PRECEDENT is a Phase II randomized controlled trial comparing vintafolide combined with pegylated liposomal doxorubicin (PLD) versus PLD alone in patients with platinum-resistant ovarian cancer. ${ }^{39}$ One hundred sixty-one patients were randomly assigned to the two arms at a ratio of 2:1, and the intent-to-treat population comprised 149 patients. The primary end point was DFS. PLD was administered at a dose of $50 \mathrm{mg} / \mathrm{m}^{2}$ once every 28 days, with or without intravenous vintafolide $2.5 \mathrm{mg}$ three times a week during week 1 and week 3. Etarfolatide was also used to assess the FR $\alpha$ status of tumor. This folatetechnetium conjugate agent allows single-photon emission computed tomography imaging for FR-expressing tumors. Patients selected had a very poor prognosis, having received at least two prior systemic cytotoxic agents after primary optimal debulking and platinum-based chemotherapy, or were considered primarily or secondarily platinum resistant. Subjects included in the intent-to-treat group were those with measurable disease. In the vintafolide group, patients had undergone more previous courses of systemic 
chemotherapy than the group receiving PLD alone. Median DFS was statistically better in the subjects taking PLD plus vintafolide than in the PLD-alone subjects (5.0 months versus 2.7 months; $P=0.31$ ). No difference was observed in OS between the two groups. A higher incidence of CA-125 response was observed in the vintafolide-plus-PLD group. In the subgroup showing a high level of FR expression in all lesions, determined by single-photon emission computed tomography with etarfolatide (FR 100\%), a greater benefit was observed in the PLD-plus-vintafolide group, with DFS of 5.5 months, versus 1.5 months in the PLD-alone group. In the same subgroup, an improvement in OS was also noted. In patients with FR-positive but less expressed disease (FR 10\%-90\%), the important benefits were not as marked, and no benefit of vintafolide addition was found in the group of patients not expressing FR. Regarding toxicity, the frequency of leukopenia, neutropenia, abdominal pain, and peripheral sensory neuropathy was statistically higher in the vintafolide group. Other gastrointestinal, blood, neurologic, and mucosal toxicities were similar in the two groups. The authors explained this increase in toxicities by "the higher frequency of safety evaluation and higher cumulative doses experienced by these patients." ${ }^{39}$ Nevertheless, these results confirm the great potential of vintafolide for the treatment of patients with platinum-resistant ovarian cancer, for whom current standard therapies are of no real benefit. ${ }^{40}$ It offers better control of the disease, even as third- or fourth-line therapy, than PLD alone as second- or third-line therapy. Other targeted therapies, such as bevacizumab in the Phase III AURELIA study, ${ }^{41}$ have shown similar results in recurrent platinum-resistant ovarian cancer, but with no possibility of selecting patients who are more likely to benefit from the therapy. A Phase III study on vintafolide is now needed to confirm these encouraging results.

\section{FR as an immunologic target: farletuzumab}

Farletuzumab is a humanized monoclonal antibody with high affinity for FR. ${ }^{42}$ It does not block FR $\alpha$ binding of folate or antifolate, but it has demonstrated a growth inhibitor effect on FR $\alpha$-expressing ovarian cancer cells. Its cytotoxicity is mediated via complement-dependent cytotoxicity and antibody-mediated cytotoxicity, in synergy with the taxanes. ${ }^{43}$ Primary results with this new antibody were very encouraging in platinum-sensitive recurrent ovarian cancer. ${ }^{44}$ In the Phase II trial conducted by Armstrong et al, $80 \%$ of normalization of CA-125 was observed in patients receiving farletuzumab plus carboplatin plus paclitaxel, with a complete or partial overall response rate of $75 \%$ and longer DFS than after the first cycle of chemotherapy; ${ }^{45}$ unfortunately, these promising results were not confirmed in the Phase III trial. Indeed, early in 2013, Morphotek, Inc., (Exton, PA, USA) stated that: the early results of the Phase III study of farletuzumab in combination with carboplatin and taxane in patients with platinum-sensitive epithelial ovarian cancer in first relapse did not meet the study's primary endpoint of PFS. ${ }^{46,47}$

\section{Perspectives}

A prospective randomized double-blind Phase III trial with vintafolide is currently under way (PROCEED study). ${ }^{48}$ Patients will be assigned to one of two arms, at a ratio of 1:1. The first arm includes vintafolide plus PLD in combination, and the second arm PLD alone, for patients with platinumresistant ovarian cancer. Primary and secondary resistance to platinum is permitted. Pretreatment evaluation of FR expression will be performed by etarfolatide scan. Expected enrollment is 640 patients. The primary end point is progression-free survival based on investigator assessment using response evaluation criteria in solid tumors (Response Evaluation Criteria In Solid Tumors [RECIST], v 1.1;). Secondary end points will compare OS of participants between treatment arms and controls and also confirm the low toxicities of combined treatment.

\section{Conclusion}

The profile of vintafolide has so far proved excellent, with little added toxicity and rapid and precise capture by tumoral tissue. Its mechanism of action is theoretically pleasing and it appears to have the desired effect when used in a clinical setting. The rationale for its use in ovarian cancer is based on multiple aspects: FR expression has been shown to be important in approximately $80 \%$ of ovarian cancer cases, with different levels of expression; this expression is not modified by previous courses of chemotherapy; a link between folate expression, disease aggressiveness, and platinum resistance is becoming more and more apparent; and current classical treatment does not offer any statistically significant benefits for our patients with platinum-resistant ovarian cancer.

Ovarian cancer needs new treatments, which are currently being widely investigated. Numerous clinical trials with targeted therapies are ongoing, often showing encouraging results. It is vital that we continue research aimed at improving the survival and quality of life of patients. By multiplying targets on ovarian cancer cells that are attacked simultaneously and associating targeted therapies, which 
can also be combined with "classical" chemotherapy, this could be achieved.

\section{Disclosure}

The authors report no conflicts of interest in this work.

\section{References}

1. World Health Organization. GLOBOCAN 2012: Estimated Cancer Incidence, Mortality and Prevalence Worldwide in 2012. Available from http://globocan.iarc.fr/Pages/fact_sheets_population.aspx. Accessed February 19, 2014.

2. Ovarian cancer [webpage on the Internet]. Bethesda, MD: National Cancer Institute. Available from: http://seer.cancer.gov/statfacts/html/ ovary.html. Accessed February 7, 2014.

3. Shih KK, Chi DS. Maximal cytoreductive effort in epithelial ovarian cancer surgery. J Gynecol Oncol. 2010;21(2):75-80.

4. McGuire WP, Hoskins WJ, Brady MF, et al. Cyclophosphamide and cisplatin compared with paclitaxel and cisplatin in patients with stage III and stage IV ovarian cancer. N Engl J Med. 1996;334(1):1-6.

5. Katsumata N, Yasuda M, Takahashi F, et al; Japanese Gynecologic Oncology Group. Dose-dense paclitaxel once a week in combination with carboplatin every 3 weeks for advanced ovarian cancer: a phase 3, open-label, randomised controlled trial. Lancet. 2009;374(9698):1331-1338.

6. Vergote I, Tropé CG, Amant F, et al; European Organization for Research and Treatment of Cancer-Gynaecological Cancer Group; NCIC Clinical Trials Group. Neoadjuvant chemotherapy or primary surgery in stage IIIC or IV ovarian cancer. N Engl J Med. 2010;363:943-953.

7. Chi DS, Eisenhauer EL, Lang J, et al. What is the optimal goal of primary cytoreductive surgery for bulky stage IIIC epithelial ovarian cancer (EOC)? Gynecol Oncol. 2006;103:559-564.

8. Duthie SJ. Folic acid deficiency and cancer: mechanisms of DNA instability. Br Med Bull. 1999;55:578-592.

9. Ulrich CM. Folate and cancer prevention - where to next? Counterpoint. Cancer Epidemiol Biomarkers Prev. 2008;17:2226-2230.

10. Matherly LH, Goldman DI. Membrane transport of folates. Vitam Horm. 2003;66:403-456.

11. Matherly LH, Hou Z, Deng Y. Human reduced folate carrier: translation of basic biology to cancer etiology and therapy. Cancer Metastasis Rev. 2007;26:111-128.

12. Antony AC. Folate receptors. Annu Rev Nutr. 1996;16:501-521.

13. Leamon CP, Low PS. Delivery of macromolecules into living cells: a methods that exploits folate receptor endocytosis. Proc Natl Acad Sci US A. 1991;88:5572-5576.

14. Weitman SD, Lark RH, Coney LR, et al. Distribution of the folate receptor GP38 in normal and malignant cell lines and tissues. Cancer Res. 1992;52:3396-3401.

15. Sandoval RM, Kennedy MD, Low PS, Molitoris BA. Uptake and trafficking of fluorescence conjugates of folic acid in intact kidney determined using intravital two-photon microscopy. Am J Physiol Cell Physiol. 2004;287:C517-C526.

16. Wang X, Shen F, Freisheim JH, Gentry LE, Ratnam M. Differential stereospecificities and affinities of folate receptor isoforms for folate compounds and antifolates. Biochem Pharmacol. 1992;44(9):1898-1901.

17. Shen F, Ross JF, Wang X, Ratnam M. Identification of a novel folate receptor, a truncated receptor, and receptor type beta in hematopoietic cells: cDNA cloning, expression, immunoreactivity, and tissue specificity. Biochemistry. 1994;33(5):1209-1215.

18. Crane LM, Arts HJ, van Oosten M, et al. The effect of chemotherapy on expression of folate receptor-alpha in ovarian cancer. Cell Oncol (Dordr). 2012;35:9-18.

19. Wu M, Gunning W, Ratman M. Expression of folate receptor type alpha in relation to cell type, malignancy, and differentiation in ovary, uterus, and cervix. Cancer Epidemiol Biomarkers Prev. 1999;8:775-782.
20. Chen YL, Chang MC, Huang CY, et al. Serous ovarian carcinoma patients with high alpha-folate receptor had reducing survival and cytotoxic chemo-response. Mol Oncol. 2012;6:360-369.

21. Despierre E, Lambrechts S, Leunen K, et al. Folate receptor alpha (FRA) expression remains unchanged in epithelial ovarian cancer and endometrial cancer after chemotherapy. Gynecol Oncol. 2013;130:192-199.

22. Kalli KR, Oberg AL, Keeney GL, et al. Folate receptor alpha as a tumor target in epithelial ovarian cancer. Gynecol Oncol. 2008;108(3): 619-626.

23. Siu MK, Kong DS, Chan HY, et al. Paradoxical impact of two folate receptors, FR $\alpha$ and RFC, in ovarian cancer: effect on cell proliferation, invasion and clinical outcomes. PLoS One. 2012;7(11):e47201.

24. Toffoli G, Russo A, Gallo A, et al. Expression of folate binding protein as a prognostic factor for response to platinum-containing chemotherapy and survival in human ovarian cancer. Int $J$ Cancer. 1998;79(2): 121-126.

25. Luyckx M, Leblanc E, Filleron T, et al. Maximal cytoreduction in patients with FIGO stage IIIC to stage IV ovarian, fallopian, and peritoneal cancer in day-to-day practice: a Retrospective French Multicentric Study. Int J Gynecol Cancer. 2012;22(8):1337-1343.

26. Guo WJ, Zhang YM, Zhang L, et al. Novel monofunctional platinum (II) complex Mono-Pt induces apoptosis-independent autophagic cell death in human ovarian carcinoma cells, distinct from cisplatin. Autophagy. 2013;9:996-1008.

27. Colombo PE, Fabbro M, Theillet C, Bibeau F, Rouanet P, Ray-Coquard I. Sensitivity and resistance to treatment in the primary management of epithelial ovarian cancer. Crit Rev Oncol Hematol. Epub September 8, 2013.

28. Mironava T, Simon M, Rafailovich MH, Rigas B. Platinum folate nanoparticles toxicity: cancer vs normal cells. Toxicol In Vitro. 2013;27:882-889.

29. Markman M, Rothman R, Hakes T, et al. Second-line platinum therapy in patients with ovarian cancer previously treated with cisplatin. $J$ Clin Oncol. 1991;9(3):389-393.

30. Andrews PA, Howell SB. Cellular pharmacology of cisplatin: perspectives on mechanisms of acquired resistance. Cancer Cells. $1990 ; 2: 35-43$

31. Ottone F, Miotti S, Bottini C, et al. Relationship between folate-binding protein expression and cisplatin sensitivity in ovarian carcinoma cell lines. Br J Cancer. 1997;76(1):77-82.

32. Tazi Y, Pautier P, Leary A, Lhomme C. [Chemotherapy in epithelial ovarian cancer]. Gynecol Obstet Fertil. 2013;41(10):611-616. French.

33. Leamon CP, Lovejoy CD, Nguyen B. Patient selection and targeted treatment in the management of platinum-resistant ovarian cancer. Pharmgenomics Pers Med. 2013;6:113-125.

34. Walters CL, Arend RC, Armstrong DK, Naumann RW, Alvarez RD. Folate and folate receptor alpha antagonists mechanism of action in ovarian cancer. Gynecol Oncol. 2013;131:493-498.

35. Vlahov IR, Santhapuram HK, Kleindl PJ, Howard SJ, Stanford KM, Leamon CP. Design and regioselective synthesis of a new generation of targeted chemotherapeutics. Part 1: EC145, a folic acid conjugate of desacetylvinblastine monohydrazide. Bioorg Med Chem Lett. 2006;16(19):5093-5096.

36. Reddy JA, Dorton R, Westrick E, et al. Preclinical evaluation of EC145, a folate-vinca alkaloid conjugate. Cancer Res. 2007;67: 4434-4442.

37. Lorusso PM, Edelman MJ, Bever SL, et al. Phase I study of folate conjugate EC145 (Vintafolide) in patients with refractory solid tumors. J Clin Oncol. 2012;30:4011-4016.

38. Leamon CP, Reddy JA, Klein PJ, et al. Reducing undesirable hepatic clearance of a tumor-targeted vinca alkaloid via novel saccharopeptidic modifications. J Pharmacol Exp Ther. 2011;336:336-343.

39. Naumann RW, Coleman RL, Burger RA, et al. PRECEDENT: a randomized Phase II trial comparing vintafolide (EC145) and pegylated liposomal doxorubicin (PLD) in combination versus PLD alone with platinum-resistant ovarian cancer. J Clin Oncol. 2013;31(35):4400-4406. 
40. Naumann RW, Coleman RL. Management strategies for recurrent platinum-resistant ovarian cancer. Drugs. 2011;71(11):1397-1412.

41. Pujade-Lauraine E, Hilpert F, Weber B, et al; AURELIA Investigators. AURELIA: a randomized phase III trial evaluating bevacizumab (BEV) plus chemotherapy (CT) for platinum (PT)-resistant recurrent ovarian cancer (OC). ASCO Annual Meeting 2012, Chicago, Illinois, USA, Saturday 2 June 2012. J Clin Oncol. 2012;30(Suppl 18):abstract LBA5002.

42. Ebel W, Routhier EL, Foley B, et al. Preclinical evaluation of MORAb003, a humanized monoclonal antibody antagonizing folate receptoralpha. Cancer Immun. 2007;7:6.

43. Spannuth W, Lyn Y, Merritt W, et al. Therapeutic efficacy of folate receptor $\alpha$ blockade with MORAb-003 in ovarian cancer. Gynecol Oncol. 2008;108:135 (abstract 307).

44. Konner JA, Bell-McGuinn KM, Sabbatini P, et al. Farletuzumab, a humanized monoclonal antibody against folate receptor alpha, in epithelial ovarian cancer: a phase I study. Clin Cancer Res. 2010;16(21):5288-5295.

45. Armstrong DK, White AJ, Weil SC, Phillips M, Coleman RL. Farletuzumab (a monoclonal antibody against folate receptor alpha) in relapsed platinum-sensitive ovarian cancer. Gynecol Oncol. 2013;129: $452-458$.

46. PR Newswire. Morphotek Announces Top-Line Results of a Phase III Study of Farletuzumab in Patients With Relapsed Platinum-Sensitive Epithelial Ovarian Cancer [press release]. Exton, PA: Morphotek ${ }^{\circledR}$ Inc., 2010 [March 12]. Available from: http://www.prnewswire.com/ news-releases/morphotek-announces-top-line-results-of-a-phase-iiistudy-of-farletuzumab-in-patients-with-relapsed-platinum-sensitiveepithelial-ovarian-cancer-186384621.html. Accessed February 20, 2014.
47. Esai Co., Ltd. Eisai announces results of phase III study of anticancer agent farletuzumab in patients with relapsed platinum-sensitive ovarian cancer [press release]. Tokyo, Japen: Esai Co., Ltd.; 2013 [January 11]. Available from: http://www.eisai.com/news/news201305.html. Accessed February 20, 2014.

48. Merck Sharp and Dohme Corp. A randomized double-blind phase 3 trial comparing EC145 and pegylated liposomal doxorubicin (PLD/Doxil ${ }^{\circledR /}$ Caelyx ${ }^{\circledR}$ ) in combination versus PLD in participants with platinumresistant ovarian cancer. Available from: http://clinicaltrials.gov/ct2/ show/NCT01170650. NLM identifier: NCT01170650. Accessed.

49. Toffoli G, Cernigoi C, Russo A, Gallo A, Bagnoli M, Boiocchi M. Overexpression of folate binding protein in ovarian cancer. Int J Cancer. 1997;74:193-198.

50. Bagnoli M, Canevari S, Figini M, et al. A step further in understanding the biology of the folate receptor in ovarian carcinoma. Gynecol Oncol. 2003;88:S140-S144.

51. Parker N, Turk MJ, Westrick E, Lewis JD, Low PS, Leamon CP. Folate receptor expression in carcinomas and normal tissues determined by a quantitative radioligand binding assay. Anal Biochem. 2005;338: 284-293.

52. Kelemen LE, Sellers TA, Keeney GL, Lingle WL. Multivitamin and alcohol intake and folate receptor alpha expression in ovarian cancer. Cancer Epidemiol Biomarkers Prev. 2005;14(9):2168-2172.

53. O'Shannessy DJ, Somers EB, Smale R, Fu YS. Expression of folate receptor- $\alpha$ (FRA) in gynecologic malignancies and its relationship to the tumor type. Int J Gynecol Pathol. 2013;32(3):256-268.

54. Leamon CP, Reddy JA, Haines B, Dussault I. Vintafolide: a first-in-class small molecule drug conjugate targeting folate receptor-positive tumors. Poster \#5502/12.
International Journal of Women's Health

\section{Publish your work in this journal}

The International Journal of Women's Health is an international, peerreviewed open-access journal publishing original research, reports, editorials, reviews and commentaries on all aspects of women's healthcare including gynecology, obstetrics, and breast cancer. The manuscript management system is completely online and includes

\section{Dovepress}

a very quick and fair peer-review system, which is all easy to use. Visit http://www.dovepress.com/testimonials.php to read real quotes from published authors. 